\title{
Os sistemas municipais de educação e os conselhos municipais de educação como mecanismos de gestão democrática
}

\author{
Municipal education systems and municipal education councils as democratic management \\ mechanisms
}

Los sistemas de educación municipal y los consejos de educación municipal como mecanismos de gestión democrática

\section{Resumo}

Este artigo discute sobre os Sistemas Municipais de Educação e os Conselhos Municipais de Educação como mecanismos da gestão democrática. O objetivo é refletir sobre a função dos Sistemas Municipais de Educação e dos Conselhos Municipais de Educação como mecanismos de fortalecimento da gestão democrática, compreendendo as barreiras e os avanços desses mecanismos na sociedade do capital. O problema a que esta pesquisa se propõe a responder é: Como os Sistemas Municipais de Educação e os Conselhos Municipais de Educação podem contribuir para o fortalecimento da gestão democrática no sistema educacional? A metodologia da pesquisa é qualitativa e as análises partiram de um estudo bibliográfico. Resultados: Os resultados mostram a importância da gestão do Sistema Municipal ser efetivamente permeada por esse princípio, servindo de alicerce ao fortalecimento dos espaços de participação, de construção da autonomia, de descentralização do poder local e de exercício da cidadania no âmbito do município. Bem como, as formas de escolha e a implantação dos Conselhos Escolares e de outras instâncias de envolvimento da comunidade escolar constituem passo importante para a democratização dos processos decisórios e partilhamento do poder. Conclusão: podemos concluir que a autonomia da instituição escolar e a democratização da gestão da educação exigem a participação das diferentes seções e de diferentes segmentos.

Palavras-chave: Gestão democrática; Sistemas municipais de educação; Conselhos municipais de educação.

\begin{abstract}
This article discusses the Municipal Education Systems and the Municipal Education Councils as mechanisms of democratic management. The objective is to reflect on the role of Municipal Education Systems and Municipal Education Councils as mechanisms to strengthen democratic management, understanding the barriers and advances of these mechanisms in the capital society. The problem that this research aims to answer is: How can Municipal Education Systems and Municipal Education Councils contributes to the strengthening of democratic management in the educational system? The research methodology is qualitative and the analyzes started from a bibliographic study. Results: The results showed the importance of the management of the Municipal System to be effectively permeated by this principle, serving as a foundation for the strengthening of spaces for participation, the construction of autonomy, the decentralization of local power and the exercise of citizenship within the municipality. As well as, the ways of choosing and implementing School Councils and other instances of involvement of the school community are an important
\end{abstract}


step towards the democratization of decision-making processes and the power sharing. Conclusion: we could conclude that the autonomy of the school institution and the democratization of education management require the participation of different sections and different segments.

Keywords: Democratic management; Municipal education systems; Municipal education councils.

\section{Resumen}

Este artículo discute los Sistemas Educativos Municipales y los Consejos Municipales de Educación como mecanismos de gestión democrática. El objetivo es reflexionar sobre el rol de los Sistemas Educativos Municipales y los Consejos Educativos Municipales como mecanismos para fortalecer la gestión democrática, entendiendo las barreras y avances de estos mecanismos en la sociedad capital. El problema que esta investigación pretende dar respuesta es: ¿Cómo pueden los Sistemas Educativos Municipales y los Consejos Municipales de Educación contribuir al fortalecimiento de la gestión democrática en el sistema educativo? La metodología de investigación es cualitativa y los análisis parten de un estudio bibliográfico. Resultados: Los resultados muestran la importancia que tiene la gestión del Sistema Municipal para estar efectivamente permeada por este principio, sirviendo como base para el fortalecimiento de los espacios de participación, la construcción de la autonomía, la descentralización del poder local y el ejercicio de la ciudadanía dentro de la Municipalidad. Así como, las formas de elección e implementación de los Consejos Escolares y otras instancias de participación de la comunidad escolar son un paso importante hacia la democratización de los procesos de toma de decisiones y el reparto del poder. Conclusión: podemos concluir que la autonomía de la institución escolar y la democratización de la gestión educativa requieren la participación de diferentes secciones y diferentes segmentos.

Palabras clave: Gestión democrática; Sistemas de educación municipal; Consejos municipales de educación.

\section{Introdução}

A gestão dos sistemas de ensino e das escolas vêm sendo remodelados desde a Constituição Federal de 1988, a Reforma do Estado na década de 1990, o fortalecimento do Estado Neoliberal e a estruturação da LDB 9394/96. Esses pontos influenciaram as novas formas de gestão da educação, apresentando a descentralização, autonomia e participação como possibilidades de direcionamento dessa gestão para os municípios e a escola.

O objetivo deste estudo é refletir sobre a função dos Sistemas Municipais de Educação e dos Conselhos Municipais de Educação como mecanismos de fortalecimento da gestão democrática, compreendendo as barreiras e os avanços desses mecanismos na sociedade do capital. Para tal, descreve as bases legais da formação dos Sistemas Municipais de Educação, amplia a discussão sobre autonomia na sua construção e organização, analisa a composição e o caráter dos Conselhos Municipais de Educação e debate sobre a categoria participação nos Conselhos Municipais de Educação.

O problema a que esta pesquisa se propõe a responder é: Como os Sistemas Municipais de Educação e os Conselhos Municipais de Educação podem contribuir para a fortificação da gestão democrática no sistema educacional? Onde algumas questões trarão norte a esta escrita: Quais as bases legais para a criação dos Sistemas Municipais de Educação? Qual o conceito de autonomia se entende nestes Sistemas Municipais de Educação no contexto do Estado Neoliberal? Qual a composição e o caráter dos Conselhos Municipais de Educação? Como ocorre a participação nos Conselhos Municipais de Educação?

Este trabalho é relevante ao passo que busca descortinar e ampliar o debate sobre autonomia nos Sistemas Municipais de Educação no contexto do Estado Neoliberal, bem como perceber os limites e condições da participação nos Conselhos Municipais de Educação, refletindo ainda nestes mecanismos como possibilidades de fortalecimento da gestão democrática.

\section{Caminhos Metodológicos}

Considerando as particularidades dessa temática, a abordagem da pesquisa é qualitativa, onde segundo Bogdan e Biklen (1994), o investigador é o instrumento principal, valoriza-se mais o processo do que os resultados ou simples produtos e o significado dos fatos têm importância vital. A investigação foi realizada através de pesquisa bibliográfica na tentativa de responder as questões norteadoras elencadas anteriormente. Para fundamentar essa produção serão utilizados trabalhos de 
autores como Dublante e Cardozo (2020), Bordignon e Gracindo (2000), Alves (2018), Freire (1996), Sousa (2012), Barroso (2013), Paro (1997), Werle (2012), Teles (2001), entre outros que irão dialogar conosco ampliando a discussão sobre o tema proposto.

\section{Resultados e Discussões}

a) Sistemas Municipais de Educação: Dispositivos legais e os aspectos da autonomia em sua organização

Inicialmente podemos destacar os aspectos legais da Constituição Federal de 1988 assim como a LDB 9394/96 como normativos legais que propõe a criação dos Sistemas Municipais de Educação. Como bem destaca Dublante e Cardozo (2020), é neste período de redemocratização do país que os municípios passam a serem responsabilizados como prioritários na oferta da Educação Infantil e do Ensino Fundamental. Juntamente com o apoio da União e dos estados, os municípios ficaram encarregados de garantir o acesso e a permanência desses alunos na rede pública.

Outro ponto importante a ser observado a respeito da Constituição Federal de 1988 foi o destaque dado ao processo de descentralização e municipalização da educação reconhecendo o município como instância administrativa, oportunizando aos mesmos a organização de seus próprios sistemas de ensino. Para Dublante e Cardozo (2020, p. 39) "[...] a explicitação das responsabilidades e competências atinentes ao município na organização da educação brasileira, definindo-o como sistema de ensino, possui relação direta com o modelo federativo adotado pelo Brasil a partir da CF de 1988".

A LDB 9394/96 em seu artigo 15 determina que: "Os sistemas de ensino assegurarão às unidades escolares públicas de educação básica que os integram progressivos graus de autonomia pedagógica e administrativa e de gestão financeira, observadas as normas gerais de direito financeiro público". É necessário aqui fazer algumas reflexões sobre esta autonomia administrativa e financeira, como também refletir sobre os aspectos da descentralização considerando o contexto de reorganização do Estado neoliberal a partir da década de 1990.

Para Flach (2020) pensar sobre a constituição do SME é importante, sobretudo no contexto brasileiro, pois historicamente tivemos uma centralização do poder governamental. Propor aos municípios a elaboração de seu próprio SME pressupõe o desenvolvimento de sua autonomia na efetivação das políticas educacionais que estão sob sua responsabilidade bem como $\theta$-a participação da sociedade nesse processo (Pereira, 2018). Devemos considerar que o desenvolvimento da autonomia, bem como a construção de uma educação de qualidade só será possível pelas vias da gestão democrática da educação e um forte compromisso com a escola pública.

Apesar de os municípios disporem agora desta autonomia na administração de seus sistemas educativos, isso não garante de fato que estas transformações aconteçam por estarem descritas na lei. Para Bordignon e Gracindo (2000, p. 148), "[...] requer mais do que simples mudanças nas estruturas organizacionais; requer mudança de paradigmas que fundamentem a construção de uma Proposta Educacional [...] ela precisa estar para além dos padrões vigentes, comumente desenvolvidos pelas organizações burocráticas”.

Como considera Barroso (2013), este processo de reforço da autonomia das escolas e dos Sistemas Municipais de Educação se desenvolvem num contexto mais amplo e mais complexo que carece de uma análise crítica, no sentido de perceber as reais intenções e condições desse processo de descentralização. Não estamos aqui defendendo a centralização administrativa da União sobre os Sistemas Educacionais, nossa intenção é provocar uma reflexão que nos permita enxergar a tentativa do Estado neoliberal em resolver sua crise de governabilidade do sistema de ensino. Barroso (2013) denomina essa crise como "governo sobrecarregado", devido ao aumento repentino do sistema educativo, os novos grupos de alunos que agora compõem esta escola (heterogeneidade social e cultural) dada a universalidade do ensino, a crise orçamentária para garantir o funcionamento deste sistema educativo e outros fatores que estão diretamente ligados a crise do capital. 
Neste sentido é que o papel deste Estado tem se redefinido principalmente desde a Reforma do Estado brasileiro de 1990, que segundo Alves (2018, p. 136) "[...] segue, de forma implícita ou explícita uma gama de diretrizes neoliberais, dentre elas podemos destacar o controle do Estado em seus gastos com pessoal, com receitas e despesas em todos os setores".

Este processo de descentralização desencadeado por essa nova organização do Estado sugere uma transferência de "poderes" e funções nacionais e regionais para o nível local, onde a escola passa a assumir o papel de gestora de seus processos juntamente com a comunidade local. Para tanto, Barroso (2013, p. 21) adverte que: "Embora este movimento decorra sob o signo da "descentralização" e da "desburocratização", as medidas tomadas fogem à dicotomia tradicional (centralizado/descentralizado) e configuram soluções mistas e diversificadas, muitas vezes de sentido público oposto". O que se percebe então nesse discurso da descentralização e autonomia administrativa das escolas não é uma transferência de poderes, mas um processo de mascaramento de que no pacote também há uma transferência, para os Sistemas Municipais de Educação e as escolas, das contradições e problemas que o Estado não pode resolver.

Nesta mesma esteira, Paro (1997, p. 13) adverte que: "Sem esquecer que o autoritarismo assume variadas formas. [...] O autoritarismo se dá também, e em especial, quando o Estado deixa de prover a escola de recursos necessários à realização e seus objetivos". Neste contexto do estado capitalista percebemos um jogo político-econômico estruturado de tal forma que se perpetue o fracasso da escola pública, supondo uma autonomia pedagógica, administrativa e financeira às escolas, para que as mesmas administrem a "falta de recursos". Neste campo minado pelo capital e com poucas possibilidades de superação ao fracasso, percebemos na gestão democrática da educação meios para que de fato se desenvolva a autonomia e a participação seja na gestão desses sistemas municipais de educação como no "chão da escola".

Sobre o desenvolvimento da autonomia e participação, Paro (1997) chama atenção ao fato de que não basta disponibilizar os espaços de participação nos sistemas de ensino, mas é necessário observar a qualidade destes espaços. "Não basta, entretanto, ter presente a necessidade de participação da população na escola. É preciso verificar em que condições essa participação pode tornar-se realidade" (Paro, 1997, p. 40).

Assim, construir um processo democrático na gestão dos Sistemas Municipais de Educação e na escola, requer um compromisso político com a melhoria da escola pública buscando garantir a participação dos diferentes sujeitos na construção do Plano Municipal de Educação bem como o Projeto Político-Pedagógico de cada escola, desde as etapas de elaboração, acompanhamento e avaliação. Para Bordignon e Gracindo (2000, p. 160): "A função da avaliação é a de buscar alternativas que permitam a correção de rumos, a transformação da realidade, o caminhar da realidade presente, da situação identificada, para a realidade futura desejada".

Esta avaliação precisa acontecer em conjunto com a comunidade escolar de modo que o poder não esteja assentado no gestor e sua equipe gestora, mas que de fato este processo democrático permita que o poder esteja assentado sobre o coletivo, e aqui destacamos o papel dos Conselhos neste movimento de democratização da escola pública. Deste modo, Alves e Barbosa (2020, p. 3) compreendem que: "A democracia denota participação, construção coletiva, representando a ideia de prática social, o que deve ser algo permanente na escola".

Como ressalta Sousa (2012), precisamos superar o aspecto formal da outorga da autonomia para a escola, não se trata de sua dimensão jurídico-administrativa, não é por que foi decretado que se tem autonomia construída. Como bem observa Freire (1996, p. 107): "Ninguém é autônomo primeiro para depois decidir. A autonomia vai se constituindo na experiência de várias, inúmeras decisões, que vão sendo tomadas. [...] A autonomia, enquanto amadurecimento do ser para si, é processo, é vir a ser. Não ocorre em data marcada".

Desse modo, é na escola que se constrói o projeto pedagógico, onde a gestão assume uma perspectiva de construção da autonomia em seu processo educativo, uma vez que este processo de transferência administrativa pelo Estado não garante uma participação ativa da comunidade. Bordignon e Gracindo (2000, p. 170) advertem que: "A escola autônoma é aquela que 
constrói no seu interior o seu projeto, que é a estratégia fundamental para o compromisso com sua realização". Para tanto, Sousa (2012, p. 41) assevera que: "A busca pela construção e implantação da autonomia da escola [...] requer clareza a respeito da razão última pela qual esses processos devem ser realizados".

Haja vista que Barroso (2013) caracteriza a autonomia como um conceito relacional, o faz no sentido de que sempre somos autônomos de alguém ou alguma coisa, assim estamos envolvidos em um sistema de relações. Somos mais ou menos autônomos em certos momentos da vida, para tal, confirma a ideia de que não se dá pronta e acabada, mas necessita de um esforço proposital no processo de construção. É uma ação de conquista da autonomia, não é algo que se pode dar a alguém, mas precisa ser estimulado a desenvolver. Por tanto, Bittar (2007, p. 317) indica que "uma educação voltada para a disseminação de uma cultura de direitos humanos tem de ser capaz, acima de tudo, de propugnar a construção de uma sociedade preparada para o exercício da autonomia, condição fundamental para o exercício da cidadania".

A escola precisa assumir a função de espaço educativo que instiga o trabalho coletivo e a formação de cidadãos autônomos, criar espaços onde a autonomia e a participação possam de fato fazer parte de seus projetos pedagógicos, desenvolver como objetivo a emancipação de seus sujeitos. Para tal, Barroso (2013, p. 27) adverte que: "Não há "autonomia da escola" sem o reconhecimento da "autonomia dos indivíduos" que a compõem".

b) Conselhos Municipais de Educação e seu caráter participativo

Após a Constituição em 1988, os CMEs passam a ser mediadores entre governo e sociedade, defendendo os direitos sociais como o direito a todos por um ensino de qualidade. E, além de ter suas antigas funções mantidas, os Conselhos também passam a atuar na fiscalização e/ou controle social, desempenhando também funções normativas, propositivas e mobilizadoras, atuando na área de políticas públicas (Werle, 2012).

De acordo com Teles (2001, p. 2), desde o Império, “[...] já havia a proposição de constituir conselhos de educação como órgãos da administração educacional. [...] Isto permite inferir, que desde o início da organização dos nossos sistemas educacionais, já se pensava em órgãos colegiados como parte da administração do setor”.

A Lei Federal $n^{\circ} 5.692 / 71$, mesmo sem autonomia, já previa a criação dos CME, porém foi posteriormente a promulgação da Constituição de 1988 "que a questão da descentralização da educação se torna lei quando se propõe a organização dos sistemas de ensino próprios da União, dos Estados, do Distrito Federal e dos municípios” (Werle, 2012, p. 108). Segundo Werle, Thum e Andrade (2008), todos os municípios são autônomos para organizar e gerir o seu sistema de ensino.

É importante que a comunidade local se mobilize na constituição da institucionalização do poder local garantida por leis e, principalmente, por um mínimo aparato legal que responda por sua estabilidade e continuidade, conduzindo assim, projetos de qualidade. A educação e seu desenvolvimento institucional, neste sentido, são apresentados como um processo permanente e não exclusivo do grupo docente e diretivo da escola. Os autores Alves \& Viegas (2019, p. 5) afirmam que para viabilizar a gestão democrática na escola e proporcionar aos integrantes do conselho uma participação consciente nas decisões, descentralizando o poder, é preciso "permitir que os cidadãos façam parte desse processo pelo diálogo, que põe no centro/priorize a vontade e os anseios de comunidades, tendo os cidadãos voz e vez no processo de decisão que lhes dizem respeito".

A LDB 9394/96, em seu teor contemplou a gestão democrática do ensino público como princípio, bem como, também instituiu o atendimento às particularidades regionais e a presença dos profissionais na construção do projeto pedagógico da escola e à grupo escolar sendo os mesmos representados por seus segmentos em Conselhos Escolares, conforme legisla a Constituição Federal de 1988.

Os Conselhos Escolares são interlocutores do poder público e da sociedade, esses atuam na defesa dos direitos educacionais assegurados nas leis em vigor. A consolidação e cumprimento dos meios de participação da comunidade escolar 
devem ser incentivadas, pensando na perspectiva de construção de novas maneiras de se partilhar esse poder de decisão nas escolas.

Nessa perspectiva, a unidade educativa, na execução e cumprimento da gestão democrática, necessita ampliar os espaços para além das discussões possibilitando a elaboração coletiva do projeto educativo como também criar e sustentar ambientes que favoreçam a participação de toda comunidade escolar. Para tanto, Araújo e Alves (2020, p. 142) acrescentam que: "É na gestão democrática que há a possibilidade de a comunidade escolar participar das tomadas de decisões de forma coletiva, despertando a autonomia desta comunidade e fortalecendo a construção de uma sociedade democrática".

Segundo Werle, Thum e Andrade (2008), os integrantes dos Conselhos são responsáveis pelo diálogo com a sociedade, atuando como instrumentos possibilitadores da democratização. Desta forma, as deficiências na composição do Conselho e na relação entre o Conselho e a sociedade impõem limites à participação democrática. Sobre o número de componentes do Conselho Escolar, Werle (2006, p. 352-353), considera que: "Se estas hipóteses são de ordem técnica, o maior número de componentes pode justificar-se do ponto de vista político. Um colegiado com maior número de componentes favorece uma diversificada representação de entidades da sociedade civil e da comunidade escolar".

Aos Conselhos Municipais de Educação compete organizar a oferta da educação básica no âmbito dos municípios e definir suas condições de funcionamento. E dependendo da forma como forem criados e organizados em cada sistema municipal de ensino, podem ter funções mobilizadoras, propositivas, deliberativas, normativas e fiscalizadoras. Cabe ainda aos Conselhos a tarefa de encaminhar o processo de elaboração dos Planos Municipais de Educação.

A configuração do Conselho Escolar difere entre os municípios, entre os estados e entre as instituições educativas. Dessa forma o quantitativo das representações sociais depende da população escolar e do tamanho da escola.

A estruturação de uma escola em que a participação seja uma realidade depende, sem sombra de dúvida, da ação de todos: dirigentes, professores, estudantes, funcionários, pais de estudantes e comunidade local. Para Habermas (apud Gutierres \& Catani, 1998, p. 62) "[...] participar significa que todos devem contribuir, com igualdade de oportunidades, nos processos de formação discursiva da vontade" ou seja "participar consiste em construir comunicativamente o consenso quanto a um plano coletivo". Pensando nisso, torna-se extremamente necessário a criação de espaços de participação, onde os participantes possam expressar-se e fazer valer os diferentes pontos de vista dentro do espaço escolar. Sobretudo, Gonçalves, Fonseca \& Souza (2021, p. 10) destacam que "uma das formas de fortalecer a gestão democrática é promover a participação da comunidade escolar e da comunidade local e que, o principal mecanismo é o conselho de escola".

$\mathrm{Na}$ unidade escolar, a participação de todos os envolvidos pode ser materializada com o funcionamento efetivo dos Conselhos Escolares ou outras organizações semelhantes como preconiza o estatuto legal na legislação vigente. Segundo Ferreira e Aguiar (2000), o compromisso que gera a participação, requer a repartição do sucesso, não apenas da responsabilidade. Então, é de suma relevância que a comunidade participe, se faça presente efetivamente, com diálogo e ideias de mudança. Portanto, faz-se necessário um trabalho coletivo que busque incessantemente a autonomia, liberdade, emancipação e a participação na construção de uma educação de qualidade para todos.

\section{Conclusões}

Com base no exposto ao longo deste artigo, podemos concluir, por meio das observações lançadas no texto, que as leis dos Conselhos Municipais de Educação e dos Sistemas Municipais de Educação dos municípios não indicam explicitamente o princípio da gestão democrática. Pensando nisto, ressaltamos a importância da gestão do Sistema Municipal ser efetivamente permeada por esse princípio, servindo de alicerce ao fortalecimento dos espaços de participação, de construção da autonomia, de descentralização do poder local e de exercício da cidadania no âmbito do município. 
De tal modo, pensar na autonomia dos Sistemas Municipais de Ensino, das instituições escolares e a democratização da gestão da educação, exigem um repensar sobre os espaços de participação, bem como a participação dos diferentes grupos dessa comunidade. Para tanto, as formas de escolha e a implantação dos Conselhos Escolares e de outras instâncias de envolvimento da comunidade escolar constituem passo importante para a democratização dos processos decisórios, possibilitando a implementação de uma nova cultura nessas instituições, por meio do aprendizado coletivo e do partilhamento do poder.

Assim, considerando que o processo de gestão é construído coletivamente e tomando a autonomia e a participação como princípios indispensáveis a democratização dos espaços escolares, compreendemos a necessidade de desenvolver futuros trabalhos que possam aprofundar os estudos no âmbito da gestão democrática apontando a importância da inserção da comunidade nos processos de gestão fomentando a descentralização do poder.

\section{Referências}

Alves, A. de S. (2018). O gerencialismo na gestão pública brasileira via parcerias público/privadas. In: Santos, T. F. (org). Diálogos sobre a educação básica. Curitiba: CRV.

Alves, A. V. V. \& Viegas, E. R. dos S. (2019). A participação nos Conselhos Municipais de Educação: entre limitações e potencialidades. Jornal de Políticas Educacionais. 13 (23).

Araújo, H. L. \& Alves, A. S. (2020). A gestão da educação e as múltiplas implicações do capital para seu conceito e aplicação. In: Zaparoli, W. G. \& Alves, A. S. (Orgs.) Estado da arte em educação: Nepan.

Barroso, J. (2013). O reforço da autonomia das escolas e a flexibilização da gestão escolar em Portugal. In: Ferreira, N. S. C. (org). Gestão democrática da educação: atuais tendências, novos desafios. Cortez.

Bittar, E. C. B. (2007). Educação e metodologia para os direitos humanos: cultura democrática, autonomia e ensino jurídico. In: Silveira, R. M. G. et al. (Orgs.). Educação em direitos humanos: fundamentos teórico-metodológicos. Editora Universitária.

Bogdan, R., \& Bilklen, S. (1994). Investigação qualitativa em educação: uma introdução à teoria e aos métodos. Porto Editora.

Bordignon, G. \& Gracindo, R. V. (2013). Gestão da educação: o município e a escola. In: Ferreira, N. S. C. (org). Gestão democrática da educação: atuais tendências, novos desafios. Cortez.

Brasil. (1996). Lei no 9.394 de 20 de dezembro de 1996. Estabelece as Diretrizes e Bases da Educação. http://www.planato.gov.br.

Brasil. (1998). Constituição (1988). Constituição da República Federativa do Brasil. Senado.

Dublante, C. A. S. \& Cardozo, M. J. P. B. (2020). Democratização da gestão do ensino público em sistemas municipais de educação do Maranhão. In, RBPAE, 36 (1), 37-55. https://seer.ufrgs.br/rbpae/article/view/95751/56987

Flach, S. de F. (2020) A gestão democrática nos sistemas municipais de ensino do Paraná: uma análise a partir dos conselhos municipais de educação. In. Ensaio: aval. pol. públ. Educ., Rio de Janeiro, 28 (106), 221-240. https://www.scielo.br/pdf/ensaio/v28n106/1809-4465-ensaio-S010440362019002701338.pdf

Ferreira, Naura S. C. \& Aguiar, M. A. S.(orgs.). (2000) Gestão da Educação: Impasses, perspectivas e compromissos. Cortez.

Freire, P.(1996) Pedagogia da Autonomia: saberes necessários à prática educativa. Paz e Terra.

Gutierrez, G. L. \& Catani, A. M. (2000) Participação e gestão escolar: Conceitos e potencialidades. In: Ferreira, N. S. C. (org.). Gestão da Educação: Impasses, perspectivas e compromissos. Cortez.

Paro, V. H. (1997) Gestão Democrática da Escola Pública. Editora Ática.

Pereira, S. M. (2018) O Sistema Municipal de Ensino em análise: avanços e desafios. In. Ensaio: aval. pol. públ. Educ. Rio de Janeiro, 26 (101), 1372-1392, out./nov. https:/www.scielo.br/pdf/ensaio/v26n101/1809-4465-ensaio-S0104-40362018002601066.pdf

Sousa, L. C. M. (2012) Autonomia da Escola: um instigante e complexo princípio educacional. CRV.

Santos, S. R. R.(2012) Avanços e limites da gestão colegiada para a democratização do ensino: resultado parcial de uma investigação no município de São Luís-MA. In: Lima, F. C. S., Lima, L. M. \& Cardozo, M. J. P. B. (Orgs.). Políticas educacionais e gestão escolar: os desafios da democratização. São Luís: EDUFFMA, p. 209-223.

Teles, R. M. (2001) O papel dos Conselhos de Educação na formação dos sistemas educacionais brasileiros. In: Reunião Anual da ANPED, 24, 2001, Caxambu. Trabalhos apresentados... Caxambu: ANPED. <www.anped.org.br/reunioes/24/P0522902106281.DOC>.

Werle, F. O. C. (2006) Gestão da educação municipal: composição dos Conselhos Municipais de Educação do Rio Grande do Sul. Ensaio: avaliação e políticas públicas em educação. Rio de Janeiro, 14 (52), 349-364. 
Research, Society and Development, v. 10, n. 6, e49910616077, 2021

(CC BY 4.0) | ISSN 2525-3409 | DOI: http://dx.doi.org/10.33448/rsd-v10i6.16077

Werle, F. O. C., Thum, A. B. \& Andrade, A. C. (2008) O Sistema Municipal de Ensino e suas implicações para a atuação do Conselho Municipal de Educação. Revista Brasileira de Política e Administração da Educação, 24, 79-109.

Werle, F. O.C., Hameister J. L., \& M. Bauer. (2012) Conselhos Municipais de Educação: Qualificação da Educação Básica e Gestão Democrática. Revista Pleiade, Foz do Iguaçu .12 (12), 7-32. 